[Agr. Biol. Chem., Vol. 34, No. 5, p. 715 723, 1970]

\title{
Studies on Respiratory Enzymes in Rice Kernel
}

\section{Part III. Physicochemical and Enzymatic Properties of Peroxidase 556 from Rice Embryo}

\author{
By Shoji IDA, Ikuo KITAMURA and Yuhei MoRita \\ The Research Institute for Food Science, Kyoto University, Kyoto \\ Received September 11, 1969
}

\begin{abstract}
Rice embryo peroxidase 556 was purified to the extent as indicated by the absorbance ratio, $\mathrm{RZ}$ greater than 4.0. The enzyme was found to be major basic component among isoenzymes of rice embryo. The preparation was homogeneous as examined by sedimentation analysis, and the sedimentation coefficient, $s^{\circ}{ }_{20, w}$, was $3.76 \mathrm{~S}$. The prosthetic group of the enzyme was identified as protohematin and its content was $1.36 \%$. The minimum molecular weight was calculated to be 46,700 . From the typical spectra of ligand-enzyme compounds, peroxidase 556 was found to react with carbon monoxide, cyanide, fluoride, and azide. However, at neutral $\mathrm{pH}$, neither fluoride nor azide reacted with the enzyme. The high affinity of the enzyme to ammonia was one of the most remarkable characteristics of the enzyme. The hydrogen peroxide compounds I and II have been observed in the enzymic reaction, and therefore rice embryo peroxidase 556 is also concluded to follow the common reaction mechanism of plant peroxidases. Overall results show the close resemblance of rice embryo peroxidase 556 with wheat germ peroxidase 556 and hemoprotein 550 .
\end{abstract}

Although an enormous number of investigations has been reported to indicate the presence of peroxidases in a wide range of the plant species, a few workers has been able to obtain highly purified or cystalline preparations from Cruciferea plants such as horseradish $^{1-31}$ Japanese-radish ${ }^{4,51}$ and turnip. ${ }^{6,71}$ Thus enzymological information has been obtained mostly from these plant enzymes.

1) H. Theorell, Enzymologia, 10, 250 (1942).

2) D. Keilin and E. F. Hartree, Biochem. J., 49, 88 (1951).

3) L. M. Shannon, E. Kay and J. Y. Lew, J. Biol. Chem., 241, 2166 (1966).

4) Y. Morita and K. Kameda, Mem. Research Inst. Food Sci., Kyoto Univ., 12, 14 (1957).

5) Y. Morita, K. Kameda and M. Mizuno, Agr.

Biol. Chem., 25, 136 (1961).

6) T. Hosoya, J. Biochem. 47, 369 (1960).

7) G. Mazza, C. Charles, M. Bouchet, J. Ricard and J. Raynaud, Biochim. Biophys. Acta, 167, 89 (1968).
On the other hand, two kinds of crystalline peroxidase have been isolated and purified from wheat germ, but their characteristics are not so clear. ${ }^{8 \sim 11 !}$

In a previous paper ${ }^{12)}$ we reported the isolation and purification of peroxidase 556 from rice embryo as the major component having a basic property. It is interesting to obtain more detailed information about chemical and enzymatic properties of this enzyme. The present paper describes the further puri-

8) B. Hagihara, K. Tagawa, I. Morikawa, M. Shin and K. Okunuki, Nature, 181, 1656 (1958).

9) K. Tagawa, M. Shin and K. Okunuki, ibid., 183, 111 (1959).

10) K. Tagawa and M. Shin, J. Biochem., 46, 865 (1959).

11) M. Shin and W. Nakamura, ibid., 50, 500 (1961).

12) Y. Morita and S. Ida, Agr. Biol. Chem., 32, 441 (1968). 
fication of this enzyme and its some enzymatic characteristics.

\section{MATERIAL AND METHODS}

Preparation of peroxidase 556. Peroxidase 556 was prepared in the same manner as described in the previous paper from rice (Oryza sativa L.) embryos with slight modifications. Although we reported that crystalline peroxidase 556 had $R Z$ of 2.87 , this value seemed rather low compared with those of the other purified peroxidases of plant origin. So the crystalline preparation having $\mathrm{RZ}$ of about 3.0 was subjected to rechromatography on CM-Sephadex G-50 in the present work. The column was equilibrated with $0.1 \mathrm{M}$ phosphate buffer at $\mathrm{pH} 7.0$ and the elution was made with a gradient device between 0.1 and $0.2 \mathrm{M} \mathrm{Na}_{2} \mathrm{HPO}_{4}$ solution.

Spectrophotometry. Spectrophotometric measurements of peroxidase and its deaivatives were carried out with a Hitachi EPS-2 recording spectrophotometer and a Beckman DU spectrophotometer. Spectra of hydrogen peroxide compounds of the enzyme were recorded by a Hitachi RSP-2 rapid scan spectrophotometer equipped with a V-018 memoriscope.

Sedimentation analysis. Sedimentation velocity was determined with a Spinco analytical ultracentrifuge model E equipped with the Schlieren optics at $15^{\circ} \mathrm{C}$.

Hematin content. The hematin content was determined according to the method of Keilin and Hartree, ${ }_{3}^{2}$ assuming the molar extinction coefficient of pyridine protohemochromogen at $557 \mathrm{~m} \mu 34.7 \mathrm{mM}^{-1} \mathrm{~cm}^{-1} 13$ ) and the molecular weight of protohematin 635 , respectively.

Enzyme activity. Peroxidase activity was measured at $30^{\circ} \mathrm{C}$ according to the method of Chance and Maehly ${ }^{41}$ by means of a Beckman DU spectrophotometer. The concentration of hydrogen peroxide was determined by using the molar extinction coefficient $\varepsilon_{230 \mathrm{~m}: 4} 71 \mathrm{M}^{-1} \mathrm{~cm}^{-1} .151$

13) K. G. Paul, H. Theorell and Å. Akeson, Acta Chem. Scand., 7, 1284 (1953).

14) B. Chance and A. C. Maehly, "Methods in Enzymology," ed. by S. P. Colowick and N. O. Kaplan, Vol. 2, Academic Press, 1955. p. 763.

\section{RESULTS}

\section{Homogeneity of purified peroxidase 556}

Figure 1 shows an elution profile of peroxidase 556 from rice embryo on a CM-Sephadex

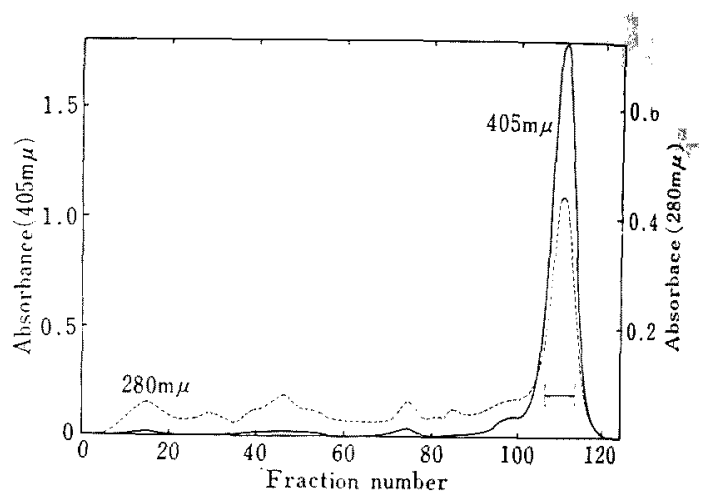

FIG. 1. Rechromatography of the Purified Peroxidase 556 on a CM-Sephadex C-50 column, 2.5x $95 \mathrm{~cm}$.

Elution was performed under a linear gradient formed with $500 \mathrm{ml}$ of $0.1 \mathrm{M} \mathrm{Na}_{2} \mathrm{HPO}_{4}$ and $500 \mathrm{ml}$ of $0.2 \mathrm{M} \mathrm{Na}_{2} \mathrm{HPO}_{4}$. Each fraction, $10 \mathrm{ml}$.

column. In addition to the major peak, several small components were separated. The major fraction obtained from this chromatography exhibited $R Z$ of 4.15 in its highest value, which is comparable to that of the purest preparation of either horseradish" or Japanese-radish. ${ }^{16}$ The purified enzyme, indicated by the horizontal arrow in Fig. 1, was tested by polyacrylamide gel electrophoresis. The enzyme migrated as a single band toward the cathode. The peroxidase 556 band was identified to be the most basic component on the zymogram of the crude extract of rice embryo. ${ }^{27}$ The highly basic nature of this

15) B. Chance, "Methods of Biochemical Analysis," ed. by D. Glick, Vol. 1, Interscience Publishers, 1954, p. 357.

16) Y. Morita and C. Yoshida, Agr. Biol. Chem., 34, 590 (1970).

17) S. Ida, H. Nikaido and Y. Morita, to be published. 


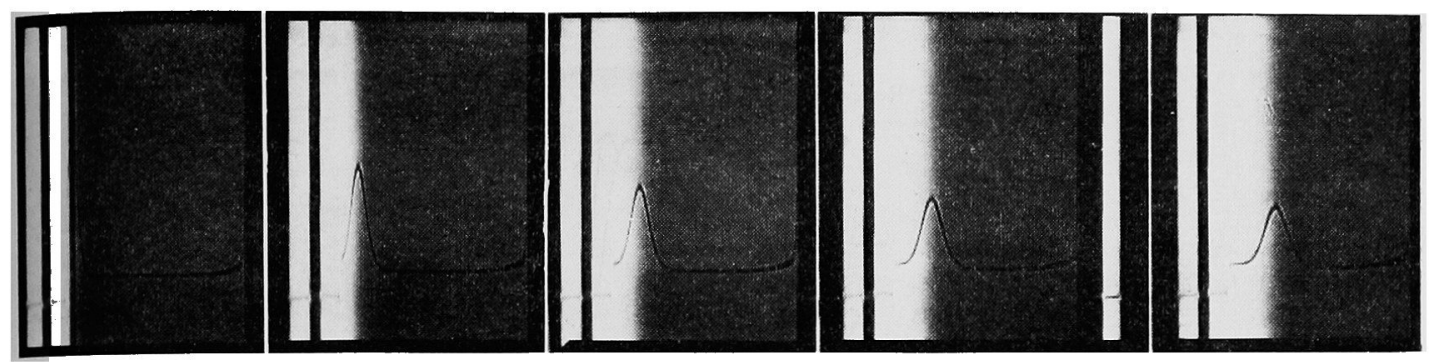

FIG. 2. Sedimentation Pattern of Peroxidase 556.

The concentration of the enzyme was $8.9 \mathrm{mg} / \mathrm{ml}$ in $0.1 \mathrm{M}$ phosphate buffer, $\mathrm{pH}$ 7.0. The photographs were taken at 9, 25, 41, 57 and 73 min after $59,780 \mathrm{rpm}$ were reached at $15.3^{\circ} \mathrm{C}$. The sedimentation is left to right.

preparation was also demonstrated from its behavior on a cation exchange chromatography. Sedimentation pattern also indicates that the preparation was homogeneous as shown in Fig. 2. The extrapolation of the sedimentation coefficients to zero concentration of the protein gave the $s_{20, w}^{\circ}$ of $3.76 \mathrm{~S}$ (Fig. 3).

The absorption spectrum of the pyridine hemochromogen revealed that the prosthetic group of this enzyme is protohematin like other plant peroxidases (Fig. 4). The hematin content of the preparation having $\mathrm{RZ}$ of 4.06 was $1.36 \%$, from which the minimum molecular weight was calculated to be 46,700 .

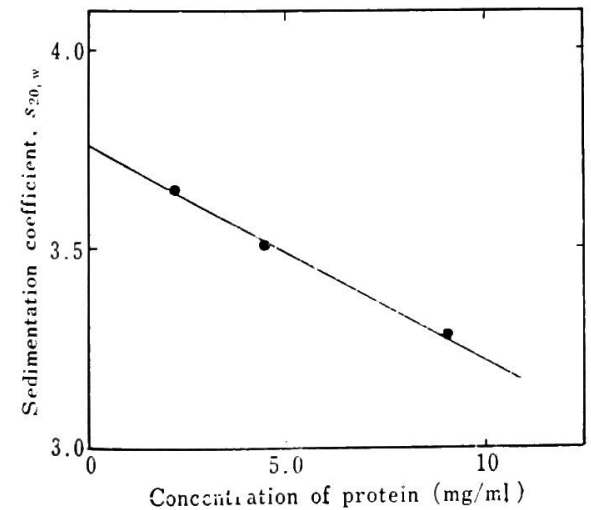

FIg. 3. Plot of Sedimentation Coefficients against Protein Concentration of Peroxidase 556.

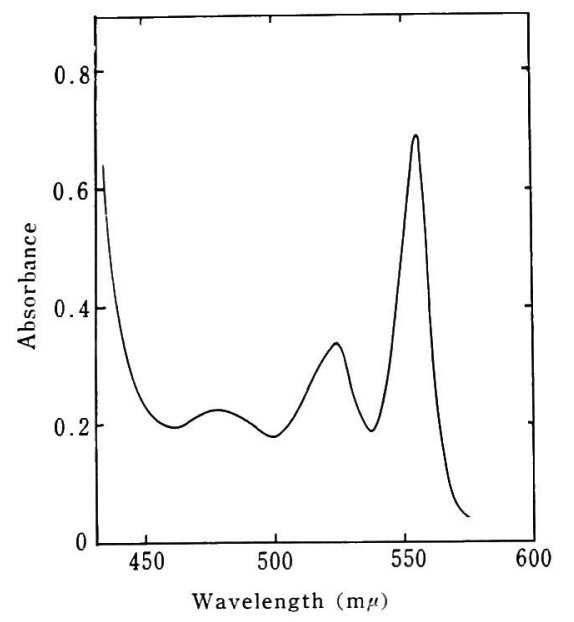

FIG. 4. Absorption Spectrum of the Pyridine Hemochromogen of Peroxidase 556.

Binding of peroxidase 556 with extrinsic ligands Absorption spectra of the enzyme and its derivatives with various extrinsic ligands are shown in Figs. 5 and 6 . The solution of the derivatives were prepared according to the method of Keilin and Hartree ${ }^{2 \prime}$ except for fluoride compound for which acetate buffer, $\mathrm{pH} 4.2$, was employed. It can be seen that absorption spectra of those compounds were similar to the absorption characteristics of horseradish peroxidase $\mathrm{II}^{2 \prime}$ and Japanese-radish 


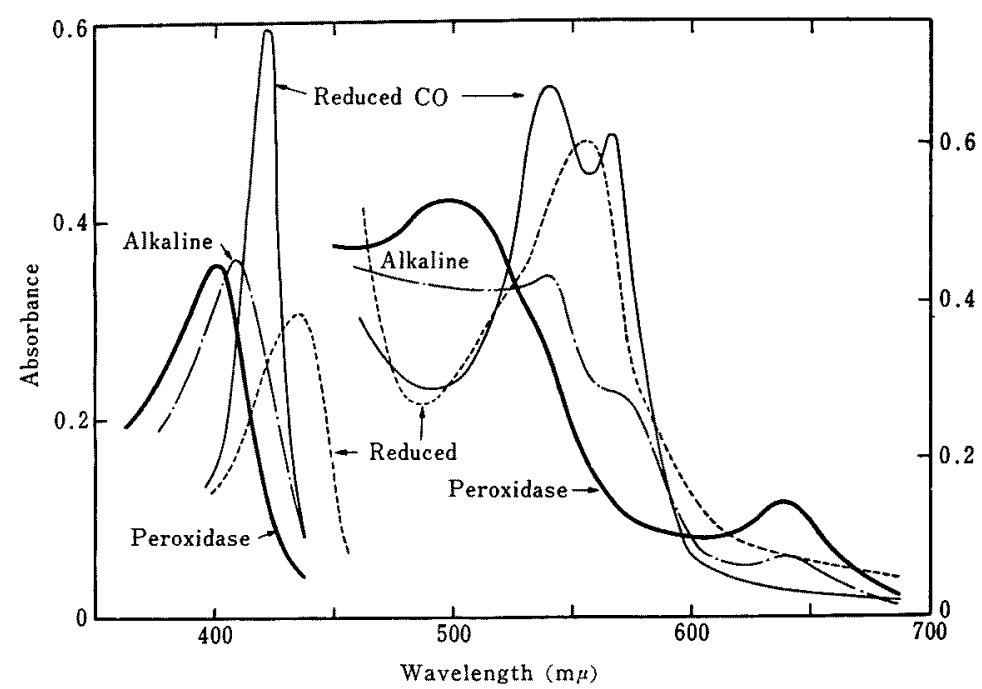

FIG. 5. Absorption Spectra of Peroxidase 556 and its Reduced, Alkaline, and Reduced CO Derivatives.

The experimental conditions are given in the text.

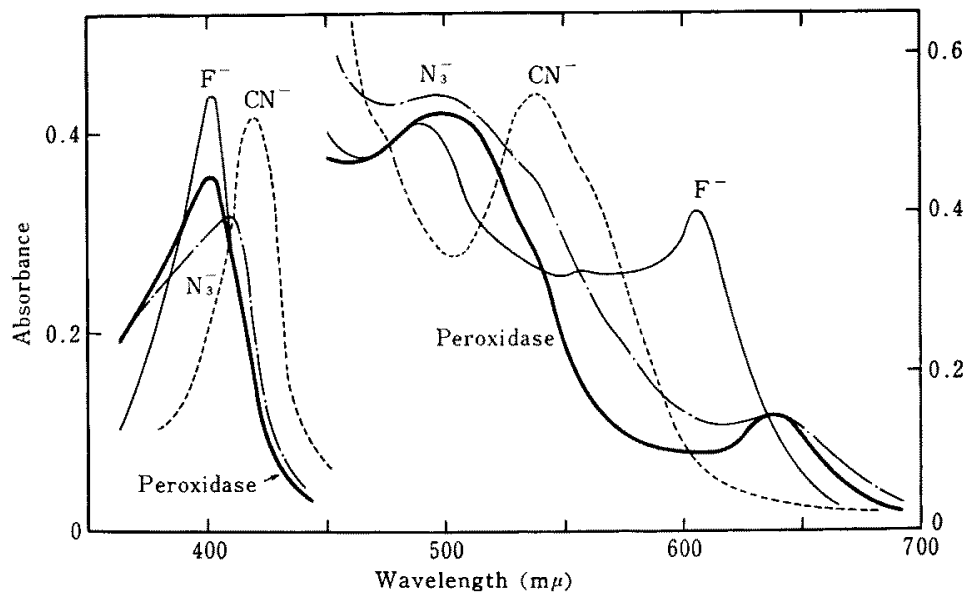

FIG. 6. Absorption Spectra of Peroxidase 556 and its Azide, Cyanide, and Fluoride Derivatives.

The experimental conditions are given in the text.

peroxidase a. ${ }^{18 /}$ However, fluoride and azide compounds were not formed at neutral $\mathrm{pH}$. Among various ligand substances examined, the result of cyanide will be particularly

18) Y. Morita, Bull. Research Inst. Food Sci. Kyoto Univ., 15, 64 (1954). noteworthy. Recently it has been shown that horseradish peroxidase I, wheat germ peroxidase 566, and Japanese-radish peroxidase c have a strong affinity toward cyanide, resulting in the occurrence of the enzyme in the cyanide-bound form. As all of these enzymes are basic in nature like rice peroxidase 556 , 
Table I. Dissociation Constants, $K$, OF Peroxidase-Cyanide Compounds

All values were determined on the ferri-enzymes.

\begin{tabular}{|c|c|c|c|c|}
\hline & & $K$ & $\mathrm{pH}$ & References \\
\hline $\begin{array}{l}\text { Rice embryo } \\
\text { peroxidase } 556\end{array}$ & \multicolumn{2}{|c|}{$5.6 \times 10^{-5}$} & 7.0 & This paper \\
\hline $\begin{array}{l}\text { Wheat germ } \\
\text { peroxidase } 556\end{array}$ & 6 & $\times 10^{-5}$ & 7.0 & 19 \\
\hline $\begin{array}{l}\text { Wheat germ } \\
\text { peroxidase } 566\end{array}$ & 8 & $\times 10^{-8}$ & 7.0 & 19 \\
\hline $\begin{array}{l}\text { Horseradish } \\
\text { peroxidase I }\end{array}$ & 3 & $\times 10^{-8}$ & 7.0 & 19 \\
\hline $\begin{array}{l}\text { Horseradish } \\
\text { peroxidase II }\end{array}$ & 2 & $\times 10^{-6}$ & 9.15 & 19 \\
\hline $\begin{array}{l}\text { Japanese-radish } \\
\text { peroxidase a }\end{array}$ & 3 & $\times 10^{-6}$ & 8.0 & 20 \\
\hline $\begin{array}{l}\text { Japanese-radish } \\
\text { peroxidase c }\end{array}$ & 5 & $\times 10^{-7}$ & 8.0 & 20 \\
\hline
\end{tabular}

it seemed worthwhile to elucidate whether or not peroxidase 556 from rice embryo has a similar property toward this ligand. Then the dissociation constant for cyanide was determined by the titration of oxidized enzyme with cyanide at $\mathrm{pH} 7.0$. Table I shows that the dissociation constant of this ligand is fairly high. It is interesting to learn that the constant for rice embryo enzyme is quite similar to that for wheat germ peroxidase 556 . The similarity is well corresponding with the fact that both enzymes occur in high-spin type as the native form.

During the course of purification of peroxidase 556 , we often observed that the color of enzyme changed from brown to red by adding ammonium sulfate and the reversal change of color by desalting on a Sephadex G-25 column. This led us to study the binding of the enzyme with ammonia. Figure 7 presents the spectral change of oxidized peroxidase 556 treated with ammonium chloride at

19) I. Yamazaki, R. Nakajima, H. Honma and M. Tamura, "Structure and Function of Cytochromes" ed. by K. Okunuki, M. D. Kamen and I. Sekuzu, Tokyo University Press, 1967, p. 552.

20) Y. Morita, C. Yoshida and S. Ida, Agr. Biol. Chem., 33, 436 (1969).

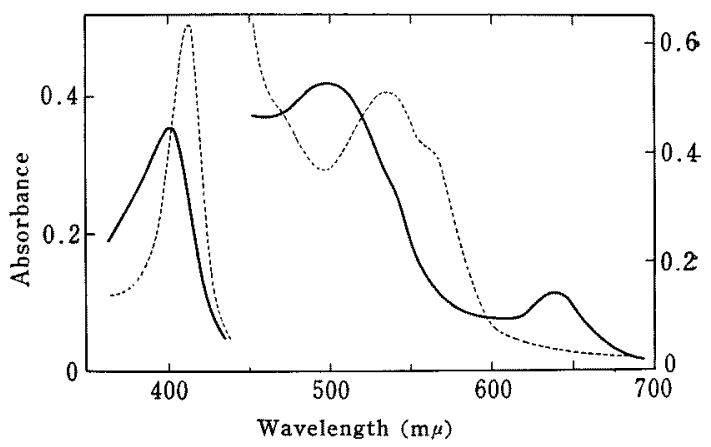

FIG. 7. Absorption Spectra of Peroxidase 556 and its Ammonia Compound.

The solution contained $2.0 \mathrm{M}$ ammonium chloride in phosphate buffer, pH 8.0. Solid line, peroxidase 556; broken line, ammonia compound.

$\mathrm{pH}$ 8.0. The Soret band of peroxidase-ammonia complex is much sharper than free peroxidase, and the absorption maximum is at $412.5 \mathrm{~m} \mu$. In order to determine the species of the ligand, i.e., protonated or non-protonated ammonia, the dissociation constant was determined by the titration of the enzyme with ammonium chloride at $\mathrm{pH} 7.0,8.0$ and 9.0. While the absorption spectrum of free peroxidase 556 did not change in this $\mathrm{pH}$ range, the quantity of peroxidase-ammonia complex increased as the $\mathrm{pH}$ was raised from 7 to 9 . Thus it seems likely that the non-protonated ammonia could react as a ligand. From the known value of the dissociation constant of the protonation of ammonia, $5.689 \times 10^{-10}$ at $25^{\circ} \mathrm{C}^{211}$ the concentration of ammonia was calculated at each $\mathrm{pH}$, and the dissociation constant of peroxidase-ammonia complex was determined to be $2.1 \times 10^{-3}$ This value was approximately constant at three different $\mathrm{pH}$ 's. This fact supported the view that the ligand might not be protonated ammonia but it should be non-protonated ammonia. However, the experiments so far carried out do not permit a clear decision on the question whether

21) S.P. Datta and A. K. Grzybowski, "Biochemists' Handbook," ed. by C. Long, E. and F. N. Spon Ltd. $1961, p .43$. 
$\mathrm{NH}_{4} \mathrm{OH}$ or $\mathrm{NH}_{3}$ reacts with peroxidase to form the complex.

\section{Hydrogen peroxide compounds of peroxidase 556}

It has been well known that peroxidase forms three distinct compounds with hydrogen peroxide: Compound I, Compound II, and Compound III, each having its characteristic absorption spectrum. ${ }^{1,22 \sim 241}$ As described in the previous paper, ${ }^{121}$ rice embryo peroxidase 556 exhibited comparable rate constants, $k_{1}$ for hydrogen peroxide and $k_{4}$ for guaiacol, similar to those for the common plant perox- regions. As our failure would be due to the so-called endogenous substrate in the preparation of lower purity and partly due to unfavorable conditions of the experiments, the stable intermediate Compounds I and II could not accumulate predominatly. After some preliminary experiments using the highly purified prepatation, we have found that peroxidase 556 forms relatively stable Compounds $I$ and II in an acidic solution. As shown in Fig. 8A. Compound I of the enzyme was formed rapidly upon the addition of $20 \mu \mathrm{M}$ hydrogen peroxide to $5 \mu \mathrm{M}$ peroxidase in con-

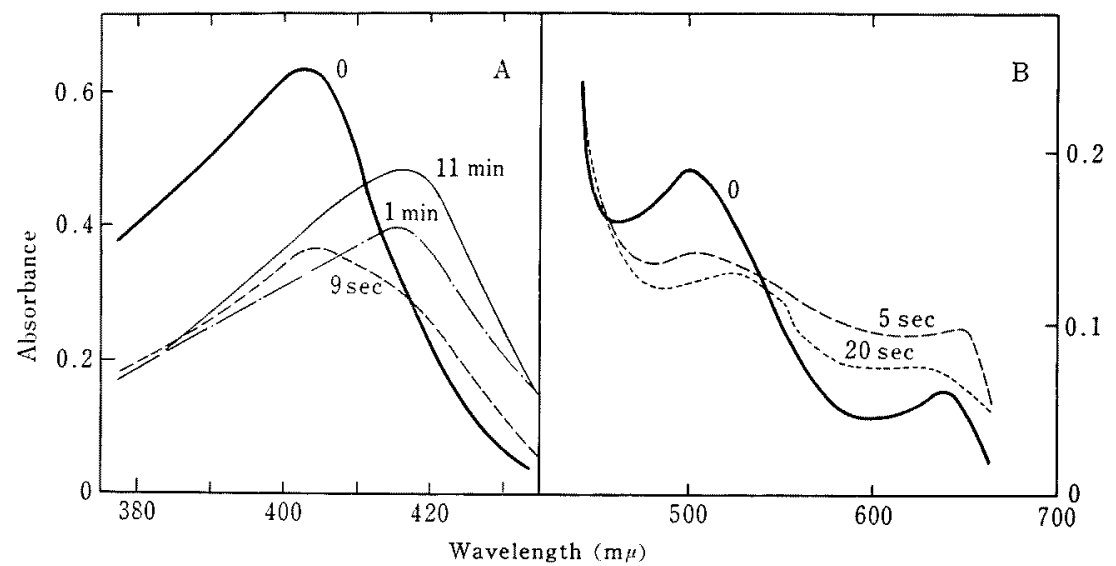

FIG. 8. Change of Absorption Spectra in Soret (A) and Visible (B) Bands of Peroxidase 556 with Time after Addition of Hydrogen Peroxide.

Curves were obtained after the addition of $20 \mu \mathrm{M} \mathrm{H} \mathrm{H}_{2} \mathrm{O}_{2}$ to $5 \mu \mathrm{M}$ peroxidase for the Soret band and $16 \mu \mathrm{M} \mathrm{H} \mathrm{H}_{2} \mathrm{O}_{2}$ to $14 \mu \mathrm{M}$ peroxidase for the visible region, respectively, in $0.02 \mathrm{M}$ acetate buffer, $\mathrm{pH} 4.4$.

idases. However, we have been able to detect neither typical Compound I nor Compound II of the rice embryo enzyme at neutral $\mathrm{pH}$ by a succesive addition of hydrogen peroxide and ascorbate. Thus, the compounds of the common plant peroxidases should exhibit the discrete absorption maxima, but peroxidase 556 showed a continuous broad band over visible

22) B. Chance, Arch. Biochem., 21, 416 (1949).

23) B. Chance, ibid., 41, 404 (1952).

24) D. Keilin and T. Mann, Proc. Roy. Soc. London, 122B, 119 (1937). centrations. Similarly the formation of Compound I was observed in the visible region by adding $16 \mu \mathrm{M}$ hydrogen peroxide to $14 \mu \mathrm{M}$ enzyme (Fig. 8B). As seen in Fig. 8A, in 9 sec after addition of the substrate Compound I was formed, and even at this time Compound I was converted partially to Compound II. In less than 1 min Compound I was completely converted to Compound II, which was rather stable and remained more than $15 \mathrm{~min}$. Addition of ascorbic acid at this time changed the spectrum of compound I into that of the free enzyme in less than a few seconds (Fig. 9). 


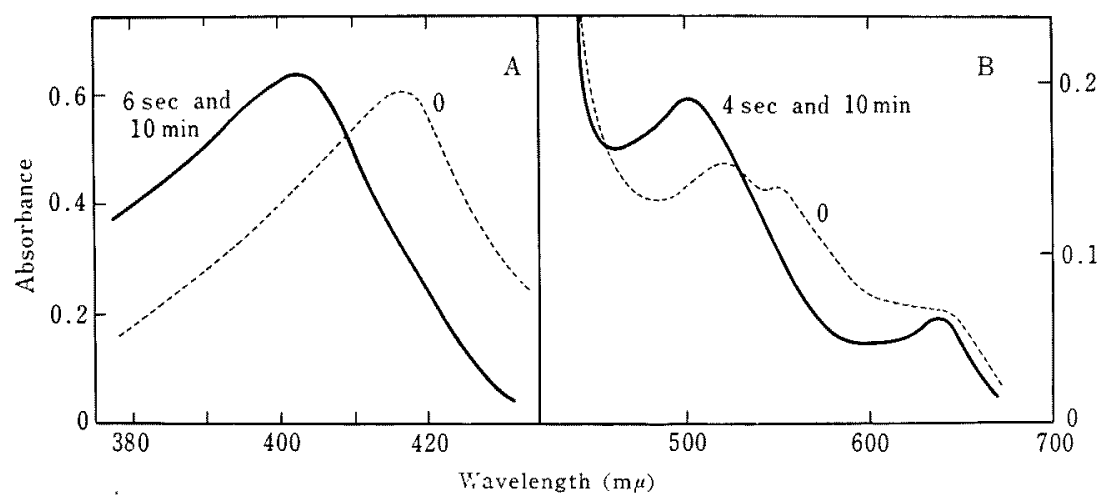

FIG. 9. Changes of Absorption Spectra in Soret (A) and Visible (B) Bands of Hydrogen Peroxide-Peroxidase Compound with Time after Addition of Ascorbic Acid.

Curves were obtained after the addition of $40 \mu \mathrm{M}$ and $20 \mu \mathrm{M}$ ascorbic acid in the Soret and the visible bands, respectively, to the hydrogen peroxide-peroxidase compound, preliminarily formed as in the cases of Fig. 8.

Table II. The Rate Constants, $k_{1}$ for Hydrogen Peroxide and $k_{4}$ for Guaiacol, of Peroxidase 556 from Rice Embryo

\begin{tabular}{lccccc}
\hline & $\mathrm{pH}$ & $\begin{array}{c}\text { Temperature } \\
{ }^{\circ} \mathrm{C}\end{array}$ & $\begin{array}{c}k_{\mathrm{I}} \\
\mathrm{M}^{-1} \mathrm{sec}^{-1}\end{array}$ & $\begin{array}{c}k_{4} \\
\mathrm{M}^{-1} \mathrm{sec}^{-1}\end{array}$ & References \\
\hline Rice embryo peroxidase 556 & 4.3 & 30 & $3.0 \times 10^{6}$ & $1.9 \times 10^{5}$ & This paper \\
Rice embryo peroxidase 556 & 6.8 & 30 & $3.2 \times 10^{6}$ & $1.3 \times 10^{5}$ & This paper \\
Japanese radish peroxidase a & 7.0 & 20 & $4.2 \times 10^{6}$ & $7.6 \times 10^{4}$ & 20 \\
Japanese radish peroxidase $\mathrm{c}^{a}$ & 7.0 & 20 & $3.6 \times 10^{6}$ & $3.4 \times 10^{5}$ & 20 \\
Horseradish peroxidase II & 7.0 & 25 & $9.0 \times 10^{6}$ & $3.3 \times 10^{5}$ & 25,26 \\
\hline
\end{tabular}

a) PCMB-treated high-spin form.

The rate constants, $k_{1}$ for hydrogen peroxide and $k_{4}$ for guiacol, are shown in Table II together with those of other plant peroxidases for comparison. The rate constant $k_{1}$ determined at acidic and neutral conditions was not different, while $k_{4}$ at acidic $\mathrm{pH}$ was higher than that at neutral region. These facts may be related with the easier detection of Compound $I$ at the acidic side than at neutral region.

The spectrum of Compound III was obtained by addition of excess hydrogen peroxide. Since this compound of peroxidase with hydrogen

25) B. Chance, Arch. Biochem., 22, 224 (1949).

26) B. Chance, ibid., 24, 210 (1949). peroxide has been known to be enzymatically inactive, further experiments were not attempted.

\section{DISCUSSION}

A homogeneous preparation of peroxidase 556 from rice embryo has been obtained by an ion exchange chromatography. The purest enzyme exhibited the absorbance ratio, $\mathrm{RZ}$, more than 4.0 , comparable to other plant peroxidases of the highest purity. The value suggests a low content of tyrosine and tryptophan in the enzyme molecule. The preparation was found to be homogeneous by polyacrylamide gel electrophoresis and sedi- 
Table III. Comparison of Properties of Monocotyldonous Peroxidases

\begin{tabular}{|c|c|c|c|}
\hline Rice & $\begin{array}{l}\text { embryo peroxidase } \\
556\end{array}$ & $\begin{array}{l}\text { Wheat germ peroxidase } \\
\left.\qquad 56^{a}\right)\end{array}$ & $\begin{array}{l}\text { Wheat germ peroxidase } \\
\left.566^{a}\right)\end{array}$ \\
\hline \multicolumn{4}{|l|}{ Absorption } \\
\hline maxima & $\begin{array}{l}\left\{\begin{array}{l}279^{\mathrm{m} \mu} \\
403 \\
500 \\
640\end{array}\right.\end{array}$ & $\begin{array}{l}278^{m \mu} \\
400 \\
500 \\
640\end{array}$ & $\begin{array}{l}2^{m} \mu \\
(370) \\
420 \\
545\end{array}$ \\
\hline Reduced & $\left\{\begin{array}{l}436 \\
556\end{array}\right.$ & $\begin{array}{c}435 \\
(520) \\
556\end{array}$ & $\begin{array}{l}433 \\
536 \\
566\end{array}$ \\
\hline RZ ( A soret $\left._{\text {S }} / A_{\text {protein }}\right)$ & 4.06 & 3.40 & 2.62 \\
\hline Hematin content & $1.36 \%$ & & \\
\hline Sedimentation coefficiant $\left(s_{20, \mathrm{w}}\right)$ & $3.76 \mathrm{~S}$ & $3.28 \mathrm{~S}$ & $2.68 \mathrm{~S}$ \\
\hline Diffusion constant $\left(D_{20}, \mathrm{w}\right)$ & & $7.10 \mathrm{~F}$ & $7.98 \mathrm{~F}$ \\
\hline \multicolumn{4}{|l|}{ Molecular weight } \\
\hline $\begin{array}{l}\text { from chemical analysis } \\
\text { from diffusion and sedimentation }\end{array}$ & 46,700 & 45,000 & 32,000 \\
\hline Isoelectric point & strongly basic & strongly basic & strongly basic \\
\hline
\end{tabular}

a) Reference 11)

mentation analysis $(3.76 \mathrm{~S})$. The enzyme contained protohematin as the prosthetic group and the content of hematin was found to be $1.36 \%$. From these values the molecular weight was calculated to be 46,700 and that the enzyme contains one mole of protohematin per each molecule of the enzyme as in the case of most other plant peroxidases. Peroxidase 556 from rice embryo had similar molecular dimension to wheat germ peroxidase 556. Similarity between these two enzymes can be seen in Table III. Although both rice embryo and wheat germ peroxidases 556 were found to be basic like horseradish peroxidase I, Japanese-radish peroxidase $c$, and wheat germ peroxidase 566, the affinity of peroxidases 556 to cyanide was very low unlike those of the latter peroxidases. This rendered the isolated enzyme to be in a high-spin form.

The enzyme was reduced by dithionite to exhibit the absorption spectrum of high-spin nature, which also could combine with carbon monoxide as in the cases of ordinary plant peroxidases. However, the characteristics of peroxidase 556 about the affinity of the extrinsic ligand substances were found in fluoride, azide, hydroxide and ammonia. Thus peroxidase 556 shows lower affinities to fluoride and azide especially at neutral $\mathrm{pH}$ compared with other plant peroxidases. In the case of azide compound, the spectrum suggests the formation of a modified enzyme rather than the simple complex at the heme site. ${ }^{271}$ Moreover, the dissociation constant of proton from the water molecule at the sixth coordination position of the heme iron would have a higher $\mathrm{p} K_{\mathrm{H}}{ }^{+}$value and hence the spectrum of the alkaline peroxidase exhibits the mixing of the high-spin form even at $\mathrm{pH}$ more than 12.5 as shown in Fig. 5. The rice embryo enzyme easily reacts with ammonia at slightly alkaline side, resulting in the formation of ammonia parahematin compound. Thus ammonia may be a strong ligand to peroxidase 556 of rice embryo. Such a behavior of peroxidase with ammonia at room temperature has not been reported in the past, except for wheat germ hemoprotein 550 studied by

27) A. S. Brill and I. Weinryb, Biochemistry, 6, 3528 (1967). 
Wasserman and Burris. ${ }^{28}$ Ammonia is known to cause the conversion of hemoproteins from the high-spin to the low-spin type for hemoglobin, and catalase indicated by the magnetic susceptability, ${ }^{29)}$ light absorption spectrum, ${ }^{301}$ and electron spin resonance spectrum..$^{31,321}$ However, these low-spin compounds could be observed at low temperatures.

Concerning the reaction mechanism, data presented here strongly suggest that peroxidase 556 may follow the reaction scheme formulated by Chance ${ }^{331}$ for horseradish peroxidase II. Although the present enzyme is different in its origin and properties from the Cruciferea peroxidases, the catalytic reaction mechanism is the same as that of these plant enzymes. As seen in Table II the rate constant for aydrogen peroxide, $k_{1}$, of peroxidase 556 was found to be $\mathrm{pH}$-independent, while the rate sonstant for guaiacol, $k_{4}$, was $\mathrm{pH}$-dependent. These values well explained the easier detec-

28) A.R. Wasserman and R. H. Burris, Phytochemistry, 4, 413 (1965).

29) C. D. Coryell and F. Stitt, J.Am. Chem. Soc., 62, 2942 (1940).

30) H. Theorell and A. Ehrenberg, Acta Chem. Scand., 5, 823 (1951).

31) A. Ehrenberg, Arkiv Kemi, 19, 119 (1962).

32) A. Ehrenberg and R. D. Estabrook, Acta Chem. Scand., 20, 1667 (1966).

33) B. Chance, "The Enzymes," Vol. II, Part 1, ed. by J. B. Sumner and K. Myrbäck, Academic Press, 1952, p. 482. tion of Compound $I$ in the acidic medium. However, they could not explain the failure of the discrete bands of Compounds I and II in visible range in the neutral medium. Probably the rate constant for the conversion of Compound I to Compound II, $k_{7}$, would be also $\mathrm{pH}$-dependent and an important factor for the detection of the intermediate compounds. Unfortunately the determination of $k_{7}$ was impossible from the overall reaction kinetics, but it can be determined by the direct reduction experiment of Compound I by hydrogen donors using a stopped-flow apparatus.

In recent years sufficient experimental data on the peroxidase isoenzymes in higher plants have been accumulated. ${ }^{34}$ Peroxidase 556 from rice embryo was also shown to be an isoenzymic component. Preliminary study along these lines has indicated that each peroxidase isoenzyme of this tissue appears to be different in specificity toward hydrogen donors. The characteristics of the isoenzymes will be presented in a succeeding paper. ${ }^{17}$

Acknowledgment. The authors wish to express their thanks to $\mathrm{Mr}$. A. Wadano for his assistance in the preparation of the enzyme. This study was supported in part by a grant in aid for the scientific research from the Ministry of Education.

34) L. M. Shannon, Ann. Rev. Plant Physiol., 19, 187 (1968). 